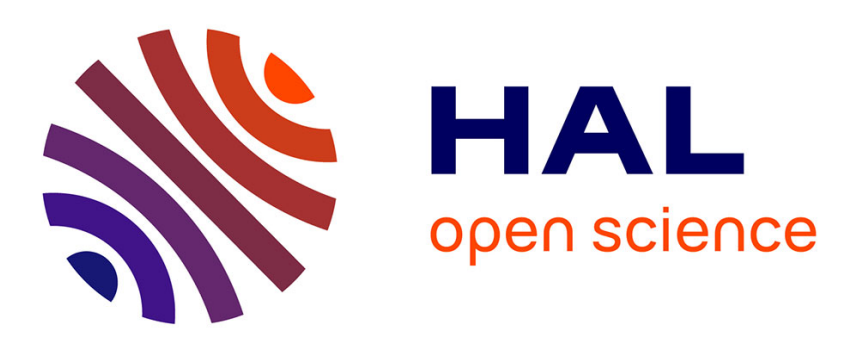

\title{
Internal solitary waves on the NW African shelf: A heuristic approach to localize diapycnal mixing hotspots
}

Mathieu Gentil, France Floc'H, Thomas Meunier, Angel Ruiz-Angulo, Gildas

Roudaut, Yannick Perrot, Anne Lebourges-Dhaussy

\section{- To cite this version:}

Mathieu Gentil, France Floc'H, Thomas Meunier, Angel Ruiz-Angulo, Gildas Roudaut, et al.. Internal solitary waves on the NW African shelf: A heuristic approach to localize diapycnal mixing hotspots. Continental Shelf Research, 2021, 226, pp.104492. 10.1016/j.csr.2021.104492 • hal-03323936

\section{HAL Id: hal-03323936 https://hal.science/hal-03323936}

Submitted on 23 Aug 2021

HAL is a multi-disciplinary open access archive for the deposit and dissemination of scientific research documents, whether they are published or not. The documents may come from teaching and research institutions in France or abroad, or from public or private research centers.
L'archive ouverte pluridisciplinaire HAL, est destinée au dépôt et à la diffusion de documents scientifiques de niveau recherche, publiés ou non, émanant des établissements d'enseignement et de recherche français ou étrangers, des laboratoires publics ou privés. 


\title{
Internal solitary waves on the NW African shelf: A heuristic approach to localize diapycnal mixing hotspots
}

\author{
Mathieu Gentil a, b, *, France Floc'h ${ }^{\mathrm{b}}$, Thomas Meunier ${ }^{\mathrm{c}}$, Angel Ruiz-Angulo ${ }^{\mathrm{d}}$, Gildas Roudaut ${ }^{\mathrm{e}}$, \\ Yannick Perrot ${ }^{\mathrm{e}}$, Anne Lebourges-Dhaussy ${ }^{\mathrm{e}}$ \\ a Univ Perpignan Via Domitia, Centre de Recherche et de Formation sur les Environnements Méditerranéens, UMR5110, 52 avenue Paul Alduy, F-66860, Perpignan, France \\ b Univ Brest, CNRS, Géosciences Océan, UMR6538, F-29280, Plouzané, France \\ ${ }^{c}$ Woods Hole Oceanographic Institution, Woods Hole, MA, USA \\ ${ }^{\mathrm{d}}$ Institute of Earth Sciences, University of Iceland, 102 Reykjavik, Iceland \\ ${ }^{\mathrm{e}}$ Institut de la Recherche pour le Développement, Laboratoire de l'Environnement MArin - UMR LEMAR/IRD/UBO/CNRS/Ifremer, Plouzané, France
}

\section{A R T I C L E I N F O}

\section{Keywords:}

Internal solitary waves

Diapycnal mixing

Kinetic energy dissipation

Acoustic backscatter

Moroccan shelf

North african upwelling system

\begin{abstract}
A B S T R A C T
Turbulent mixing on continental shelves plays roles in the structure and dynamics of marine ecosystems, nutrient cycling, primary production and dispersion of pollutants. Describing and understanding internal wave dynamics enables improved mapping of mixing over continental shelves, especially in complex environments where many processes may interact, such as in upwelling systems. This paper describes internal wave propagation and dissipation in the Moroccan upwelling system using a comprehensive set of hydrographic observations made during two in situ surveys. The acoustic backscatter of the echosounder is shown to be a rapid and convenient survey tool for detecting internal solitary waves (ISWs) on large spatial scales, through the high-frequency oscillation of the zooplankton layer during nighttime conditions. Along ISW trains, enhanced diapycnal mixing episodes are observed with increased dissipation coefficients in the thermocline $\left(\mathrm{O}\left(10^{-7} \mathrm{~W} \mathrm{~kg}^{-1}\right)\right)$, associated with overturning up to $6 \mathrm{~m}$. Mixing due to internal wave soliton packets shows large spatial and temporal variability, but contributes to the overall mixing processes and is responsible for large intermittent variations in the thermocline position. The joint use of a multifrequency echosounder and a current profiler ADCP allows mixing to be quantified (via the Richardson number) on large spatial scales. Validation and use of this method in other coastal regions could be useful to determine regional mixing parameterization in numerical models.
\end{abstract}

\section{Introduction}

\subsection{Internal waves and diapycnal mixing in the coastal ocean}

Estimation of turbulent mixing on the continental shelf is important for understanding the structure and dynamics of marine ecosystems, nutrient cycling, primary production and dispersion of pollutants (Nash et al., 2004; Pineda et al., 2020; Rippeth et al., 2005; Schafstall et al., 2010). Diapycnal mixing in the ocean is mostly driven by intermittent patches of small-scale turbulence (Müller and Briscoe, 2000). Internal waves (IWs) act as an intermediate process that transfers energy from large-scale forcing (wind and tide) to fine-scale mixing at vertical scales of a few meters.

A number of observational studies have shown that IWs are ubiquitous in the stratified ocean (Chang et al., 2021; Garrett and Munk,
1975, 1979; Helfrich and Melville, 2006; Holloway, 1987), and cover a wide spectrum, from the inertial frequency to the Brünt-Väisälä frequency, with a vertical displacements of 1-100 m. Internal tides are generated through the interaction of the barotropic tide with the topography over the continental slope and shelf (Baines, 1973; Garrett and Kunze, 2007; Llewellyn Smith and Young, 2002; St. Laurent and Garrett, 2002; Wunsch, 1975). They are highly sensitive to the ambient stratification, which controls their amplitude. Gerkema (1996) showed that internal tides generated at the shelf break tend to evolve nonlinearly and give rise to shorter-scale internal solitary waves (ISWs) as they propagate nearshore. They are associated with intense vertical shear potentially leading to super-critical Richardson numbers (a measure of the relative importance of the stabilizing effect of stratification and destabilizing effect of vertical shear). Hence, they can trigger shear instability and intense diapycnal mixing.

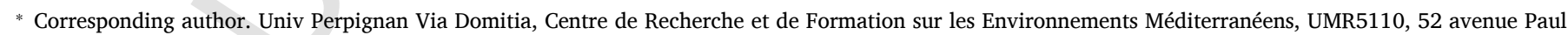
Alduy, F-66860, Perpignan, France.

E-mail address: mathieu.gentil@univ-perp.fr (M. Gentil). 
The signature of internal waves consists in a vertical displacement of the thermocline and pycnocline and these waves are commonly observed using mooring temperature time series. However, the intermittency of this process can make it difficult to detect them using occasional one-off measurements. Several studies have shown that methods based on acoustic data, commonly used in fisheries studies, make it possible to track ISWs (Apel, 2003; Moum et al., 2003; Sandstrom et al., 1989). Sandstrom et al. (1989) showed that a significant increase in acoustic backscatter is observed in the layers, generated by the passage of ISWs.

Over the past four decades, a number of studies have focused on quantifying the mixing induced by IWs (Jones et al., 2020; Lamb, 2014; MacKinnon et al., 2017; Moum et al., 2003; Palmer et al., 2015; Sandstrom and Oakey, 1995; Vic et al., 2019). However, the complex interactions of internal waves with topography mean that understanding the energy dissipation processes and quantifying IW mixing rates on the continental shelf is not an easy task and remains an active area of research (Grados et al., 2016; Hamann et al., 2018; Nash et al., 2012; Zulberti et al., 2020). As pointed out by Schafstall et al. (2010), a general parameterization of mixing for such areas is still lacking. Understanding and mapping mixing processes induced by ISWs over continental shelves is of prime importance for the parameterization of their effects in regional numerical models.

Here we present a study combining hydrological and hydrodynamical datasets, including those collected with an Acoustic Doppler Current Profiler (ADCP), multifrequency echosounder (EK60) and conductivity/temperature/depth probe (CTD), to detect ISWs and assess the increased diapycnal mixing they trigger on the NW African shelf.

\subsection{The Moroccan continental shelf}

Modeling studies of IW activity and dissipation emphasized that the Moroccan shelf is a global hotspot for IWs (de Lavergne et al., 2019; Garrett and Kunze, 2007). The Moroccan continental margin is characterized by: $1 /$ the presence of a slope break between the continental shelf and the abyssal plane with a bathymetry rising from $2000 \mathrm{~m}$ to $180 \mathrm{~m}$ over a length of $12.8 \mathrm{~km}$; 2/a well-marked thermocline; 3/a semi-diurnal tide (micro-tidal regime), with an average tidal range of $90 \mathrm{~cm}$; 4/a Coriolis parameter $\mathrm{f}=6.83 \times 10^{-6} \mathrm{~s}^{-1}$; and 5/a maximum buoyancy frequency $\mathrm{N}$ around 5 cycle. $\mathrm{h}^{-1}$ close to the value observed in the north of the system near Gibraltar (Vlasenko et al., 1996). These conditions are favorable to the generation of internal tides and their evolution into solitons (Gerkema, 1996; Yuan et al., 2020). A persistent annual upwelling subject to seasonal fluctuations is observed over the Moroccan shelf. Upwelling of cold water can be clearly seen in the sea surface temperature map in Fig. 1a (MODIS-Aqua; monthly composite). This upwelling is stronger in summer, associated with the trade-wind migration (Cropper et al., 2014). Like all upwelling regions, the Moroccan upwelling system is subject to intense mesoscale and submesoscale activity. Capet et al. (2017) suggested that the intense mixing driven by ISWs might play a key role in the upwelling dynamics. Observational evidence of ISWs on the NW African shelf was reported by Capet et al. (2017), Schafstall et al. (2010) and Arístegui et al. (2009). They found average turbulent dissipation rates of $4.9 \times 10^{-8} \mathrm{~W}_{\mathrm{kg}}^{-1}$ on the Mauritanian continental slope (Schafstall et al., 2010) and values occasionally reaching $\mathrm{O}\left(10^{-7} \mathrm{~W} \mathrm{~kg}^{-1}\right)$ on the Senegal shelf (Capet et al., 2017). However, the origin of mixing is difficult to identify over the Moroccan shelf, as many processes may contribute and interact: upwelling fronts, submesoscale filaments, large-scale canary current, tide and ISWs.

The present work describes a comprehensive set of hydrological and hydrodynamical observations collected on the Moroccan shelf. To our knowledge, the impact of ISWs has not been documented in this area. The methods and instruments used to detect ISWs are described in section 2. Section 3 then presents actual ISW activity and its effects on mixing. Finally, we discuss the validity of these observations in section 4 .

\section{Materials and methods}

\subsection{Sampling strategy}

Two surveys were carried out onboard the research vessel N/O Antea. Continuous SIMRAD EK60 echosounder and Acoustic Doppler Current Profiler (ADCP WHS $600 \mathrm{kHz}$ ) observations were recorded, with the ADCP and EK60 synchronized so that they would not generate arte- a

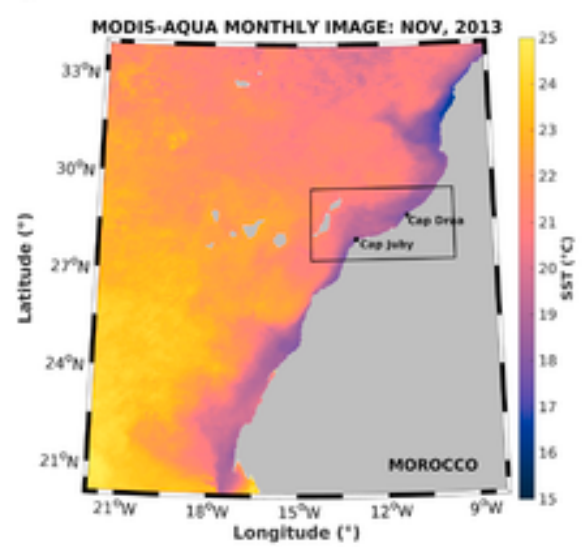

b

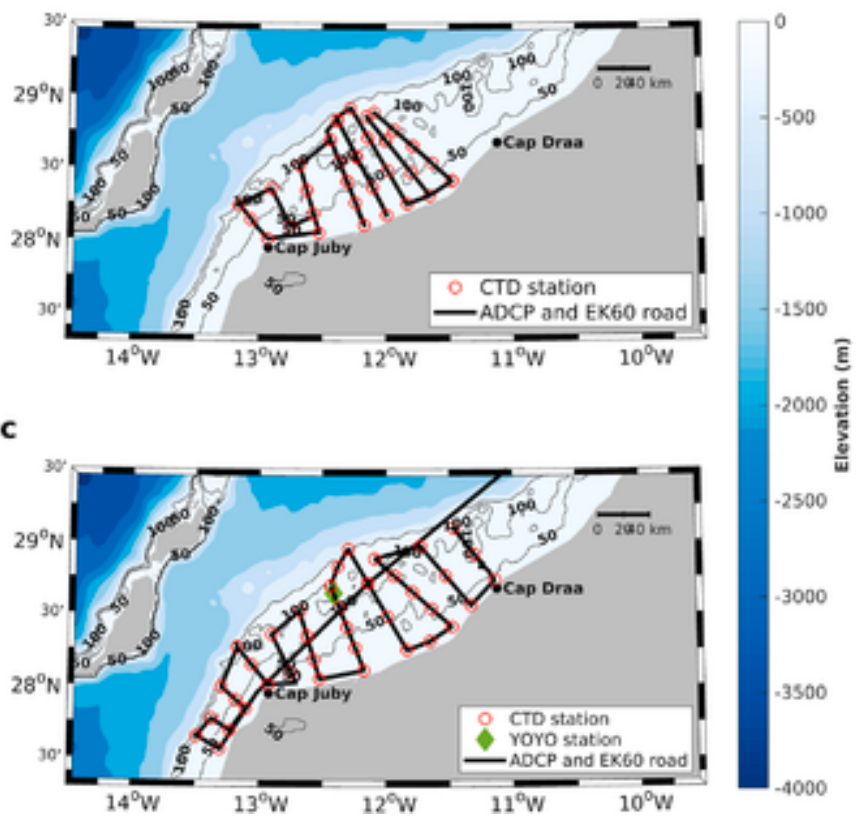

Fig. 1. a) Sea surface temperature map of the NW African upwelling system (MODIS-Aqua; monthly composite). The black rectangle indicates the sampling area. Maps of the surveys over the Moroccan shelf: b) from 28 June to July 5, 2013, EPURE 1; and c) from 7 to 17 November 2013, EPURE 3. Ship tracks with ADCP and echosounder are plotted as black thick lines, with red circles indicating CTD stations. The thin black lines are the 50, 100 and $200 \mathrm{~m}$ isobaths. During the EPURE 3 survey, a yoyo station was carried out at the position shown by the green diamond. 
facts on each other. 115 CTD (Conductivity-Temperature-Depth) stations were performed during the two cruises. The first survey took place in summer (EPURE 1: 28 June to July 5, 2013, Fig. 1b), and the second in autumn (EPURE 3: 7 to November 17, 2013, Fig. 1c). Data from both surveys were analyzed and used together as a single dataset, because ISWs are observed at both campaigns.

\subsection{CTD}

Pressure, temperature and conductivity were measured using a Seabird SBE 911-plus CTD with an acquisition frequency of $24 \mathrm{~Hz}$. Thirty-one and eighty-four stations were carried out during the first and second surveys, respectively (Fig. $1 \mathrm{~b}$ and c). Salinity and density were computed using the TEOS-10 algorithms (McDougall and Barker, 2011). Only the downcast profiles were used in the analysis to avoid data contamination by the wake of the packet and CTD frame (Alford and Pinkel, 2000). Data were smoothed using a median filter with a window size of three points, and were binned by $1 \mathrm{~m}$ depth interval. During the last survey, yoyo CTD profiles were performed (Fig. 1c), with 31 profiles done in approximately $4 \mathrm{~h}$.

The vertical resolution of $1 \mathrm{~m}$ used in this study allowed us to assess the fine-scale structures and associated turbulent mixing. To estimate the intensity of turbulent mixing, the kinetic energy dissipation rate $(\varepsilon)$ was computed using the Thorpe scale $\mathrm{L}_{\mathrm{T}}$ (Thorpe, 1977) as:

$\varepsilon=\mathrm{a}^{2} \mathrm{~N}^{3} \mathrm{~L}_{\mathrm{T}}^{2}$

where $\mathrm{a}$ is an empirical constant coefficient, $\mathrm{N}$ is the Brunt-Väisälä frequency, defined as $\mathrm{N}=\sqrt{ }(-\mathrm{g} / \rho \mathrm{x} \delta \rho / \delta \mathrm{z}), \mathrm{g}$ is the gravity acceleration $\left(\mathrm{m}^{2} \mathrm{~s}^{-1}\right)$ and $\rho$ is the density $\left(\mathrm{kg} \mathrm{m}^{-3}\right)$. Thorpe scales are a measure of the vertical scale of density overturns, which correspond to local hydrostatic instabilities of the vertical density profile. For any given vertical density profile, the Thorpe displacements $\mathrm{L}_{\mathrm{T}}$ are equivalent to the distance between a density-based unstable water parcel and its corresponding statically stable one, which is given by the difference in depth of each fluid parcel between the unsorted and sorted profiles (Thorpe, 1977). The constant a (eq. (1)) is the ratio that statistically links the Ozmidov and Thorpe scales (Dillon, 1982; Moum, 1996; Wesson and Gregg, 1994). A value of 0.8 is typically used to estimate $\varepsilon$ (Alford et al., 2015; Dillon, 1982; van Haren, 2020). The Ozmidov scale can be interpreted as the maximum vertical scale that a particle reaches when all its kinetic energy is converted into potential energy (Ozmidov, 1965). Finally, it should be noted that estimates of vertical diffusivity, $\mathrm{K}_{\mathrm{v}}$, are computed assuming constant mixing efficiency $\gamma=0.2$, so that $\mathrm{K}_{\mathrm{v}}=\gamma$ $\varepsilon \mathrm{N}^{-2}$.

\subsection{Echosounder (EK60)}

Four SIMRAD EK60 echosounders were connected to four splitbeam transducers installed facing downwards on the hull of the ship. The echosounders were managed together using ER60 software, which simultaneously operated the four frequencies 38, 70, 120 and $200 \mathrm{kHz}$ and measured backscatter throughout the water column for each frequency. Each echosounder was calibrated with a $38.1 \mathrm{~mm}$ tungsten carbide standard sphere following the calibration procedure of Foote (1987). Acquisition was set with a $3 \mathrm{~s}$ ping interval and a pulse length of $512 \mu \mathrm{s}$. The ER60 software recorded data continuously throughout the surveys.

Physical processes, such as IWs, can be observed via spatial and temporal variations in zooplankton layers, whose acoustic responses vary, according to their observed frequency and which are visible with low acquisition thresholds (no more than $-80 \mathrm{~dB}$ based on the assumption of a backscatter around $-70 /-75 \mathrm{~dB}$ for the zooplankton layers) (Bertrand et al., 2010; Pineda et al., 2020). Furthermore, Sandstrom et al. (1989) indicated that acoustic backscatter levels in turbulent patches approach
$-50 \mathrm{~dB}$ at $200 \mathrm{kHz}$, providing a rapid and convenient survey tool for estimating mixing levels induced by IWs. The 70,120 and $200 \mathrm{kHz}$ frequencies were used to characterize the spatial and temporal variability of the zooplankton layers, enabling us to establish the link with the thermocline that would validate the echosounder as a tool for IW detection. For data processing, the Matecho software was used (Perrot et al., 2018). An echo integration was applied (Fig. 2) consisting of averaging acoustic energy values on the vertical (depth) and horizontal (time or distance) scales, with a minimum backscatter threshold of $-80 \mathrm{~dB}$ (night)/-90 dB (day) and a maximum threshold of $0 \mathrm{~dB}$. This parameterization difference between day and night, with a reduction of backscatter threshold during the day to $-90 \mathrm{~dB}$ instead of $-80 \mathrm{~dB}$ at night, was made to adjust for spatial variations in zooplankton. During the day, zooplankton migrate deep into the ocean to escape from their predators, leading to a dilution of acoustic backscatter signal intensity. Echo integration was carried out from a depth of $6 \mathrm{~m}$ (to suppress noise due to bubbles at the surface), to the maximum depth (maximum acquisition depth or bottom depth). The measured volume backscattering strength (Sv) was averaged vertically every $0.5 \mathrm{~m}$ in order to detect sound-scattering layers. A semi-automatic method was then used to determine the upper and lower limits of the zooplankton layer, following Bertrand et al. (2010). A layer was manually defined in the water column on the basis of the average echogram of the three frequencies 70 , 120 and $200 \mathrm{kHz}$, from which the depths were computed that had $10 \%$ and $95 \%$ of the cumulative sum of area backscattering coefficients (MacLennan et al., 2002) (thick black lines in Fig. 2), depicting the main zooplankton layer. These thresholds are empirical and correspond to the strong backscatter intensity gradient in the zooplankton layer. Considering the noise level of these surveys, this computer-assisted expert method was proven to be more accurate and reliable than automatic treatment from the surface to the bottom.

\section{4. $A D C P$}

A ship-mounted $600 \mathrm{kHz}$ Workhorse Sentinel RDI ADCP was used to measure velocity. The device operated continuously during both sur-

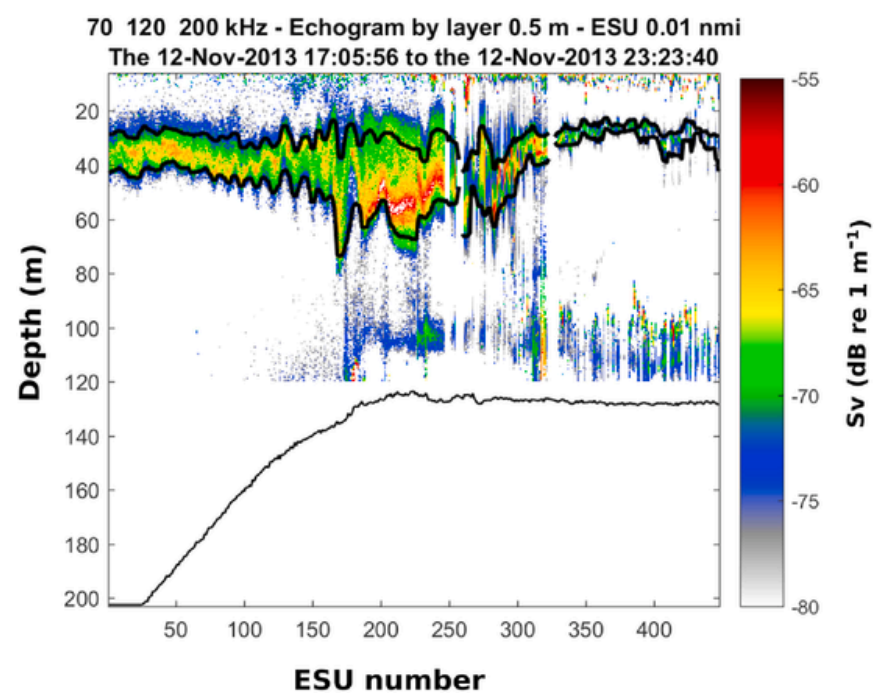

Fig. 2. Acoustic detection of the "main" zooplankton layer during the second survey. Example of an echo integration performed on the averaged echogram of the 3 frequencies 70, 120 and $200 \mathrm{kHz}$. Echo integration results, showing the variability of a sound-scattering layer (Sv), are displayed in color. The thick black upper and lower lines correspond to the depths where $10 \%$ and $95 \%$ of the cumulative sum of acoustic echoes between two manually defined vertical points are present, respectively. The thin black line corresponds to the bottom depth. Acoustic densities were averaged vertically every $0.5 \mathrm{~m}$. The x axis represents Elementary Sample Units (ESU), here we performed resampling on a linear horizontal scale with an ESU $=18 \mathrm{~m}$. 
veys (Fig. $1 \mathrm{~b}$ and $\mathrm{c}$ ). The ADCP was set to ping every second, averaging over $1 \mathrm{~min}$ giving a $1.7 \mathrm{~cm} \mathrm{~s}^{-1}$ accuracy. The magnitude of the currents and direction were measured with a vertical resolution of $1 \mathrm{~m}$ and a maximum range of $50 \mathrm{~m}$ depth. To facilitate current variability representation, the horizontal velocities $\mathrm{u}$ and $\mathrm{v}$ were averaged over $10 \mathrm{~min}$ for eastward and northward components, respectively.

Based on the ADCP velocity measurements, high resolution estimates of vertical shear were derived, which can be large in ISWs, leading to intense diapycnal mixing. ISWs propagating shoreward can be associated with shear-induced Kelvin-Helmholtz instability (Held et al., 2019; Jones et al., 2020; Moum et al., 2003). Kelvin-Helmholtz instabilities which generate mixing are characterized by a super-critical Richardson number, ie., less than 1/4 (Howard, 1961; Miles, 1961; Smyth and Moum, 2012). The Richardson number is defined as $R_{i}=N^{2} /\left(U_{z}^{2}\right)$, where $U_{z}$ is the vertical shear of horizontal velocity.

\section{Results}

\subsection{Evidence of internal waves}

Fig. 3 shows an example of ISW detection from the echosounder during the CTD yoyo station done on November 12, 2013 on the outer shelf. The propagation of an ISW train is shown by an oscillation of the high-backscatter layer (around $-60 \mathrm{~dB}$ ) from 17:50 to 20:00 UTC (Fig. 3). Maximum crest-to-trough amplitude reaches $40 \mathrm{~m}$ over the outer shelf for 15 min. The fourth CTD station (18:18 UTC in Fig. 3) shows a prominent solitary wave with amplitude $a=27 \mathrm{~m}$, located at depth $h=25 \mathrm{~m}$ in the undisturbed state ahead. This wave is therefore highly nonlinear $(a / h=1)$, and is identified in this study as a HighFrequency Oscillations (HFO), which is characterized by a period about $15 \mathrm{~min}$ and an amplitude greater than $20 \mathrm{~m}$. Twelve HFO events are observed on the shelf using the echosounder signal during both missions (eighteen campaign days). Ten of these HFO events occurred in phase with the internal tide (at high or low tide).

Fig. $4 \mathrm{a}$ and $\mathrm{b}$ shows 3 of the 31 temperature and salinity profiles from the yoyo station on the outer shelf. The rapid evolution of the

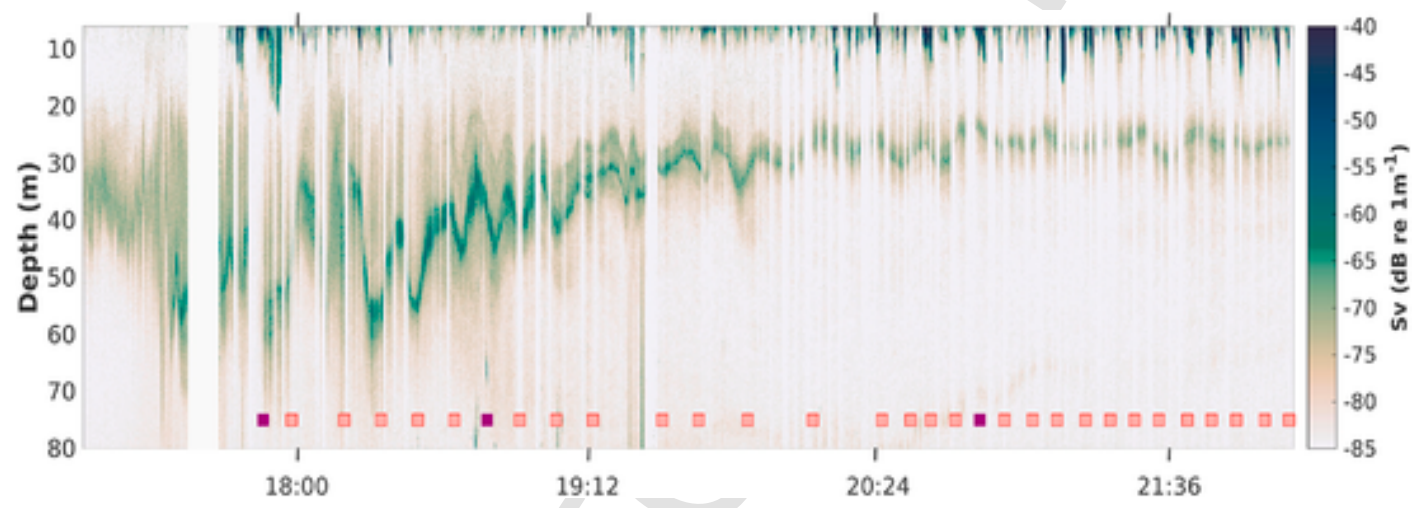

Fig. 3. Volume backscattering strength (Sv) from the $200 \mathrm{kHz}$ echosounder during the CTD yoyo station (survey 2; Nov 12, 2013). A sequence of internal solitary waves can be seen between 25 and $60 \mathrm{~m}$ depth from 17:50 to 20:00. The red squares indicate the time of the CTD casts and purple squares correspond to the three profiles displayed in Fig. 4a-b. The white vertical bands correspond to the suppressed noisy pings caused by propeller bubbles during the station.

a

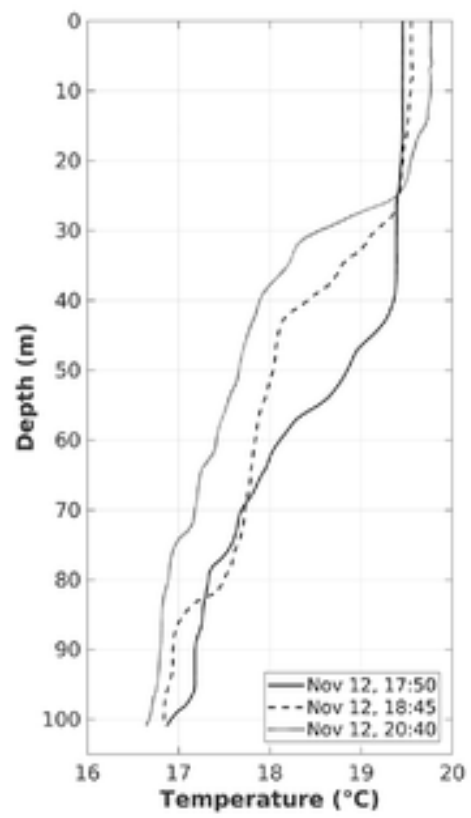

b

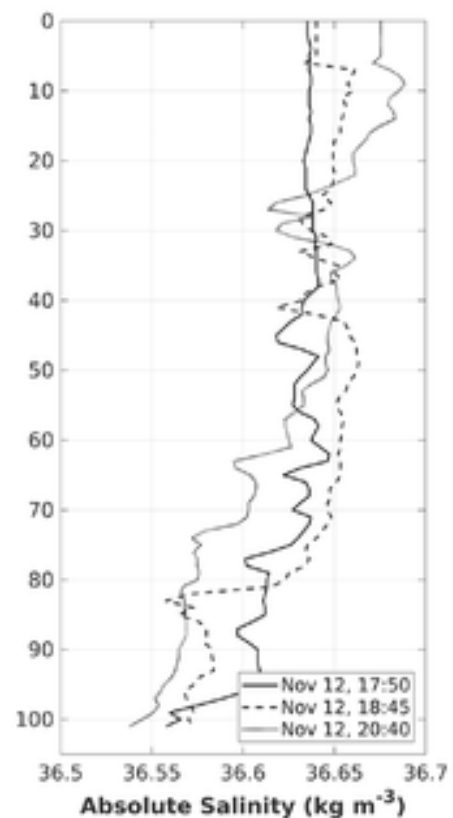

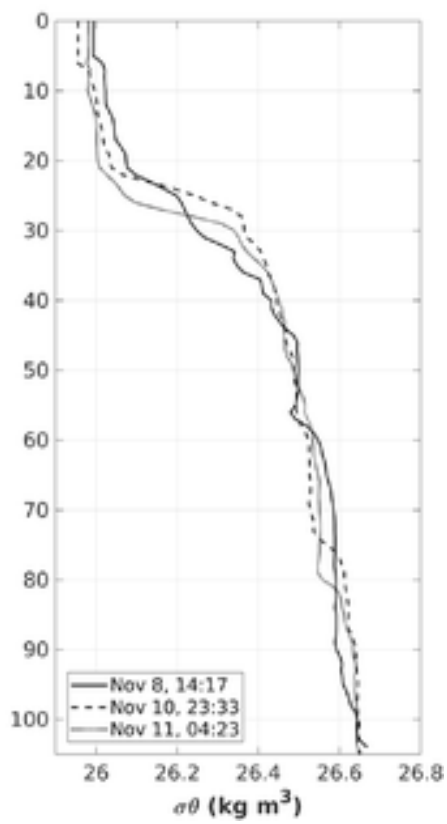

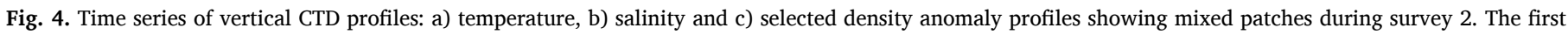
two panels correspond to the yoyo station, where an internal solitary wave packet is observed by the echosounder. 
thermocline depth is evident over the $3 \mathrm{~h}$ recording period. The top of the thermocline fluctuates from a depth of $40 \mathrm{~m}$ at 17:50 to $20 \mathrm{~m}$ at 20:40 (Fig. 4a). These profiles are indicated by purple squares in Fig. 3. The variability of the thermocline depth (Fig. 4a), is closely related to the dispersion of the zooplankton layer (purple square in Fig. 3). Salinity is relatively homogeneous (Fig. 4b), ranging between 36.55 and $36.7 \mathrm{~kg} \mathrm{~m}^{-3}$, and has a minor effect on horizontal and vertical density gradients. Fig. 4c shows three selected density anomaly profiles on the shelf during the survey 2 (Fig. 1c). On the 3 profiles, we identify a pycnocline between 20 and $30 \mathrm{~m}$ depth, separating the surface lighter water $\left(<26.1 \mathrm{~kg} \mathrm{~m}^{3}\right)$ from the subsurface denser water $\left(>26.45 \mathrm{~kg} \mathrm{~m}^{3}\right)$. Well-mixed patches are evident at different depths under the pycnocline on the three profiles. They correspond to the area where the density anomaly is vertically constant, as shown between 70 and $90 \mathrm{~m}$ depth in November 8 at 14:17 (black line in Fig. 4c). The thickness of the patches ranges between 1 and $20 \mathrm{~m}$ and are found on a majority of profiles of both legs.

Layers of strong acoustic reflectivity gradients associated with the zooplankton layer were detected using the $200 \mathrm{kHz}$ echosounder data (Fig. 5a) and the semi-automatic method described above. On the shelf, among the three frequencies used for this work, $200 \mathrm{kHz}$ showed the highest detection of the zooplankton layer. The echogram is shown in Fig. 5, along with the corresponding interpolated temperature and vertical velocity shear sections. The solid and dashed lines correspond to the mean and the lower/upper limits of the strong acoustic reflectivity gradients, respectively. Fig. 5a shows a vertical displacement of the main zooplankton layer (in green), with an amplitude of up to $40 \mathrm{~m}$. The position of the reflective layer is superimposed on a temperature section in Fig. 5b, showing a clear correspondence with the thermocline. The latter closely follows the $18.5^{\circ} \mathrm{C}$ isotherm, which separates warmer surface water $\left(18.6-20{ }^{\circ} \mathrm{C}\right)$ from colder subsurface water $\left(18.4-17^{\circ} \mathrm{C}\right)$. Furthermore, the thermocline is highly variable, with a depth ranging from $55 \mathrm{~m}$ at 18:00 to $25 \mathrm{~m}$ at 20:00. Fig. 5c shows that the upper limit of the acoustic reflectivity gradients (dashed line between 20 and $30 \mathrm{~m}$ depth) also coincides with the shear reversal depth, between the subsurface layer of positive shear and the deeper layer of negative shear. The thermocline and shear reversal depth clearly coincide between 55 and $25 \mathrm{~m}$ depth.

\subsection{Evidence of increased diapycnal mixing}

The maximum Brunt-Väisälä frequency $\left(0.6^{-1} \times 10^{-3} \mathrm{~s}^{-1}\right)$ coincides with the position of the reflective layer, showing a clear correspondence with the stratification (Fig. 6b). The pycnocline position is similar to the thermocline (Fig. 5b) and shear reversal (Fig. 5c) positions. As expected, the Richardson number (Ri) is low in the surface mixed-layer (Fig. 6c). This mixed layer is characterized by a positive shear stress (Fig. 5c). Furthermore, subcritical Ri $(<0.25)$ patches are found right below the pycnocline (Fig. 6c). However, the patches observed during the ISW train, from 17:50 to 20:00 are smaller and more scattered than the patch observed from 20:00 to 21:45. This can be explained by the depth of the pycnocline, which is on average located around $40-45 \mathrm{~m}$

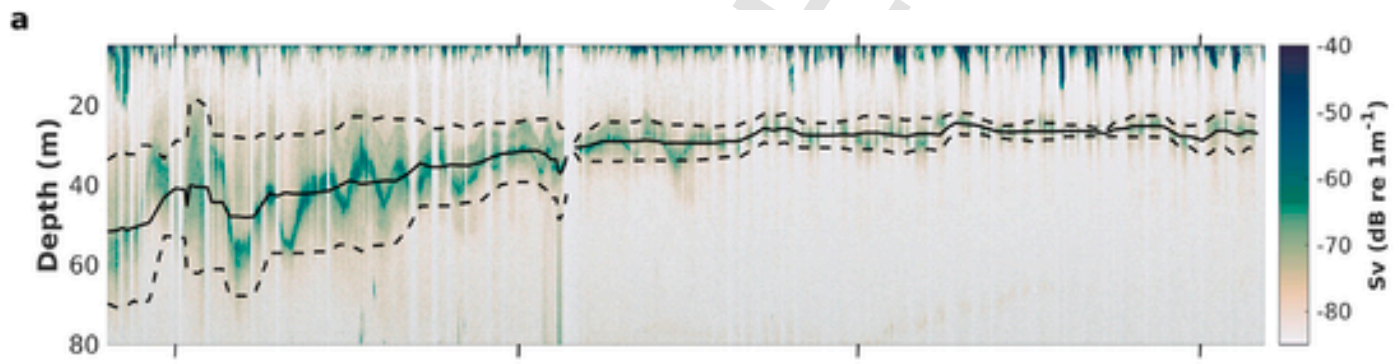

b

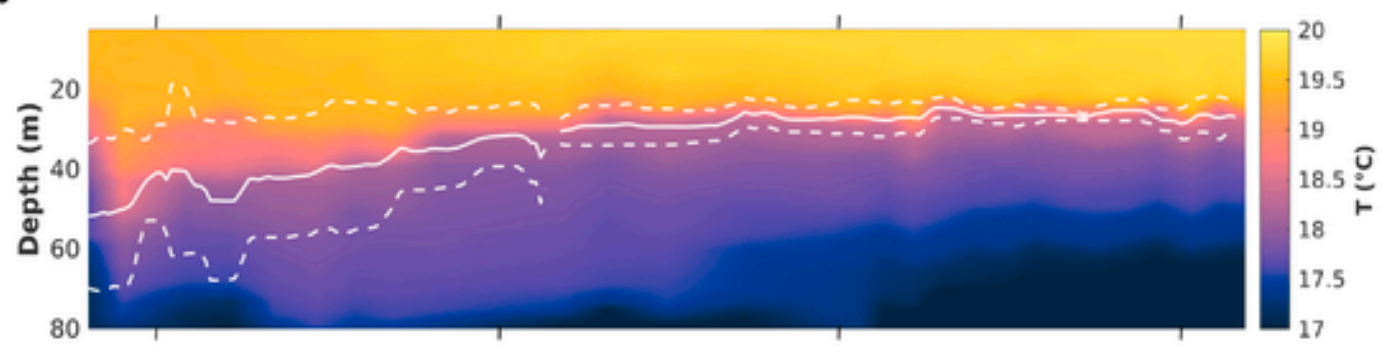

c

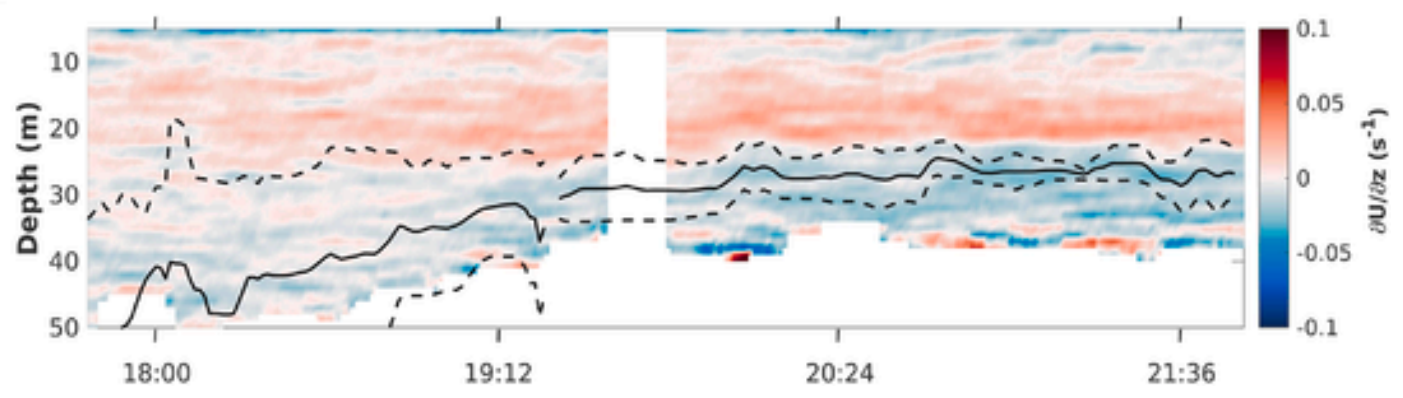

Fig. 5. A sequence of internal solitary waves. a) Volume backscattering strength from the $200 \mathrm{kHz}$ echosounder during the CTD yoyo station (survey 2; 2013/11/ 12). b) Time series of temperature temporally interpolated from CTD profiles. c) Time series of vertical shear estimated from ADCP data over the first $50 \mathrm{~m}$ (ADCP range). Large acoustic reflectivity gradients in the zooplankton layer are superimposed on all plots as black or white lines. The solid and dashed lines correspond to the mean and the lower/upper values of the strong acoustic reflectivity gradients, respectively. 
a
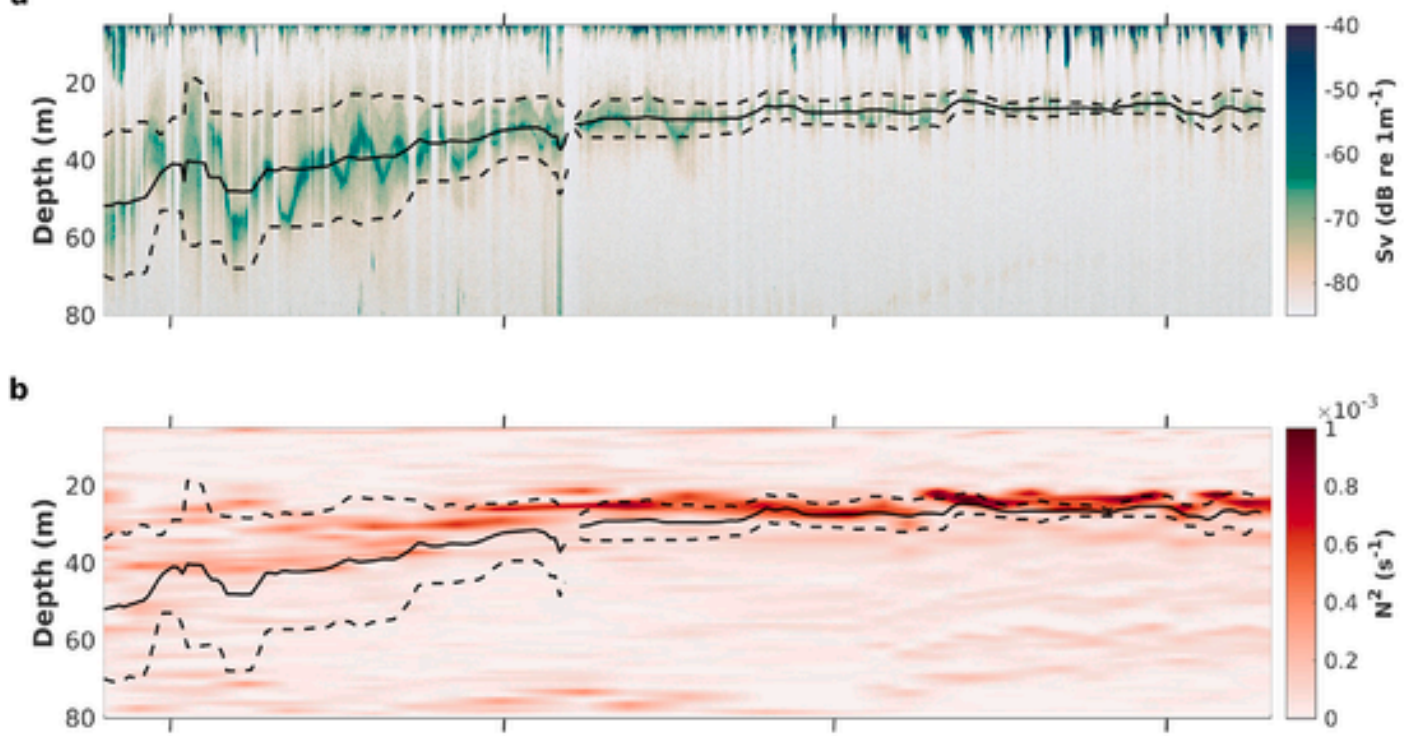

c

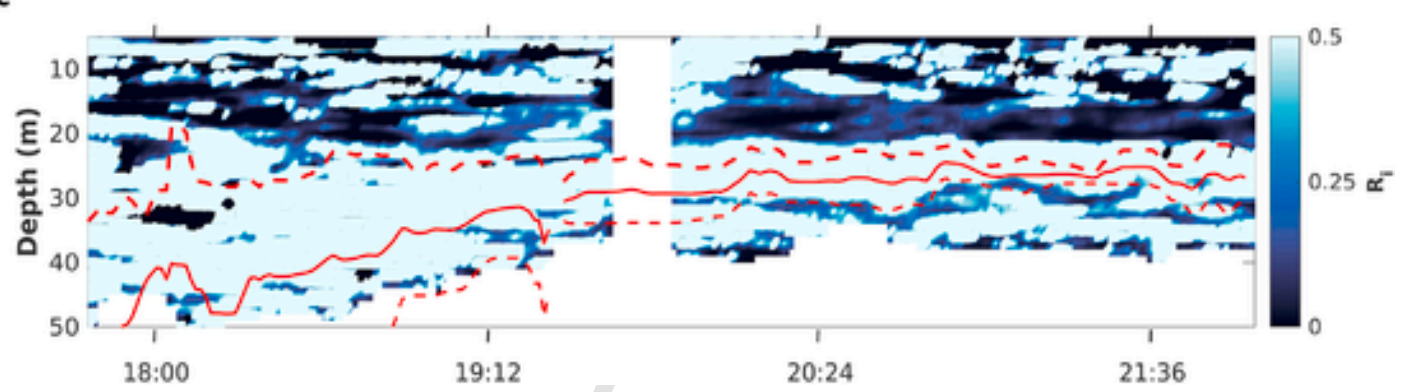

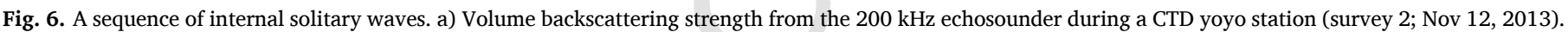

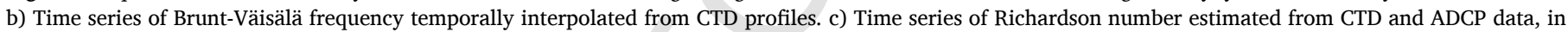

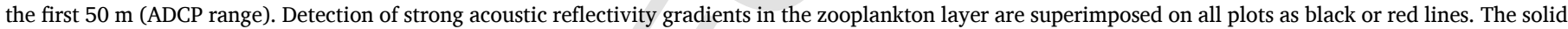
and dashed lines correspond to the mean and the upper/lower limits of the strong acoustic reflectivity gradients, respectively.

depth during the ISW train. Observation of the Richardson number patches below it are limited due to the range of the ADCP ( $50 \mathrm{~m}$ depth).

Fig. 7a depicts the ISW train recorded by the echosounder at $200 \mathrm{kHz}$; eight profiles were selected (colored squares) to show the impact of the soliton train on mixing. Fig. $7 \mathrm{~b}$ shows the variation of the thermocline depth, with well-mixed patches in the water column. These patches are associated with overturning shown by Thorpe displacements (Fig. 7c and 7a with colored circles), and an increase of dissipation ( $\varepsilon$, Fig. $7 d)$ and turbulent diffusivity $\left(\mathrm{K}_{\mathrm{v}}\right.$, Fig. 7e). In Fig. 7, $\varepsilon$ and $\mathrm{Kv}$ were normalized by their average over depth and all CTD casts $\left(<->\right.$ is the average), and displayed in logarithmic scale $\left(\log _{10}\right.$ $(\varepsilon /<\varepsilon>)$ ).

Intense mixing is common in the surface layer, because of wind and waves effects. In order to assess the impact of ISWs, we attempt to follow the evolution of overturning, dissipation and diffusion below the surface mixed layer (SML). The SML depth was calculated following de Boyer Montégut et al. (2004) using a vertical density threshold of $0.03 \mathrm{~kg} \mathrm{~m}^{-3}$ from a reference value at $5 \mathrm{~m}$ depth, to identify the base of the mixed layer (black dashed line in Fig. 7a). The SML was found at $35 \mathrm{~m}$ depth on 17:50 UTC and steadily decreased to reach $20 \mathrm{~m}$ depth. The SML is closely related to the upper limits of the strong acoustic reflectivity gradients (Fig. 6c). The Thorpe displacements associated with high values of dissipation and diffusivity are mainly located in the SML (Fig. 7a, and 7c-e). However, the Thorpe displacements reach up to $6 \mathrm{~m}$ below the SML at 17:57 UTC. Also, secondary maxima of dissipation and diffusivity are observed near the thermocline (e.g. $\varepsilon$ values reaching $\mathrm{O}\left(10^{-7}\right) \mathrm{W} \mathrm{kg}^{-1}$, two order of magnitude less than in the SML), where the amplitude of the internal wave train is the highest (profiles from 17:50 to 18:18 UTC in Fig. 7a). Overall, $K_{v}$ values are frequently in the range of $\mathrm{O}\left(10^{-11}\right) \mathrm{m}^{2} \mathrm{~s}^{-1}$. These values, recorded close to the ISW train, are two orders of magnitude larger than the integrated values in the water column: $\mathrm{O}\left(10^{-9}\right) \mathrm{W} \mathrm{kg}^{-1}$ and $\mathrm{O}\left(10^{-13}\right) \mathrm{m}^{2} \mathrm{~s}^{-1}$ for $<\varepsilon>$ and $<\mathrm{K}_{\mathrm{v}}>$, respectively.

\subsection{Relationship between acoustic backscatter and hydrological parameters}

In the ocean, high-frequency sound is scattered by many different processes. Here, two phenomena might cause the observed impedance contrasts in the water column: zooplankton content and temperature contrasts. IWs propagate along density gradients, where stratification is high. It is thought that IWs may play a role in the aggregation or transportation of zooplankton (Bertrand et al., 2010; Lennert-Cody and Franks, 1999). In the water column, marine organisms are often assumed to be the primary source of acoustic backcatter (Warren et al., 2003), and we suggest that it could be a proxy of the thermocline depth and the maximum of the stratification of the water column, where ISWs propagate.

A least squares regression method was used to estimate the relationship between the depths of the acoustic reflectivity gradient limits (Fig. 5a) and the thermocline (Fig. 5b), for both the July and November 2013 surveys. Coefficients of determination $\left(\mathrm{r}^{2}\right)$ of different dataset were highly variable, ranging between 0 and 0.81 . Correlations were made separately for day and night conditions, due to the different acoustic backscatter thresholds used for these two conditions (see 2.3 
a
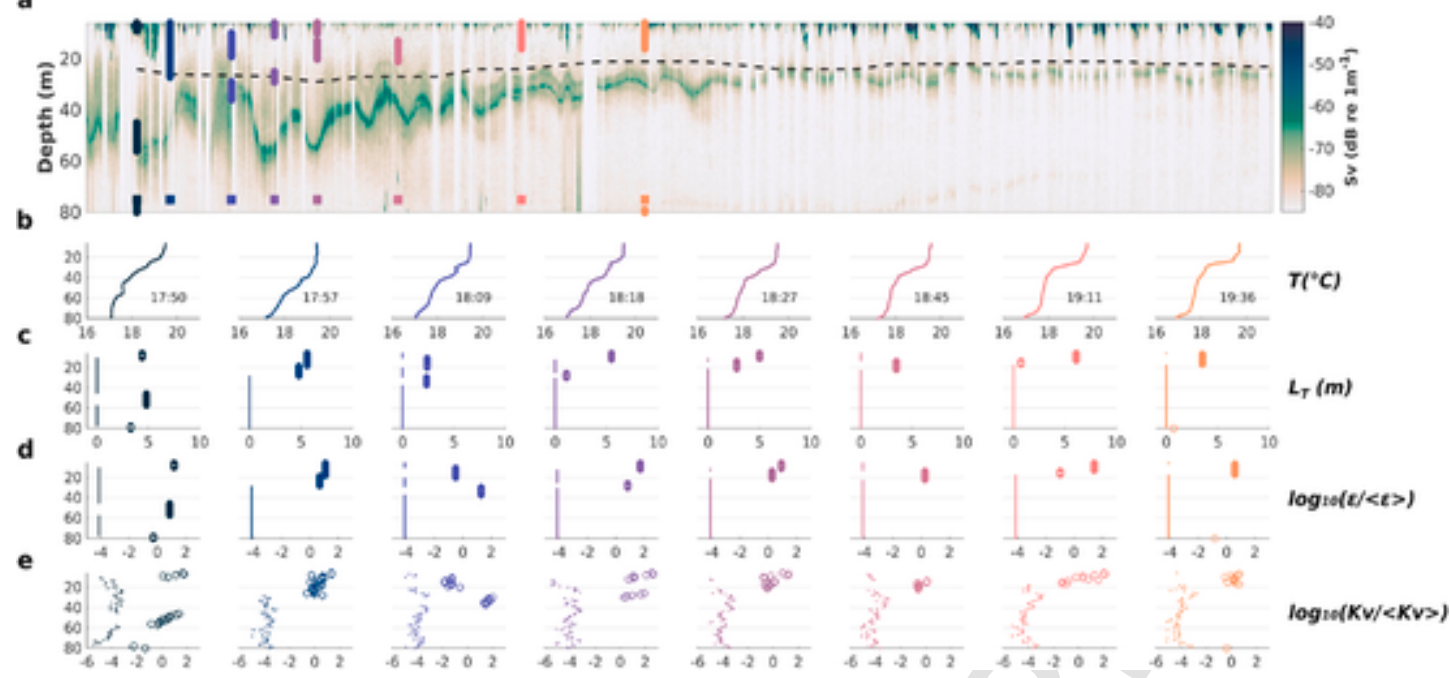

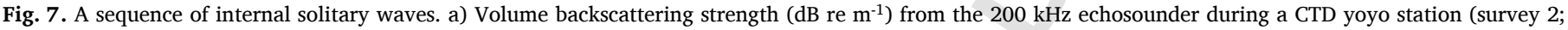

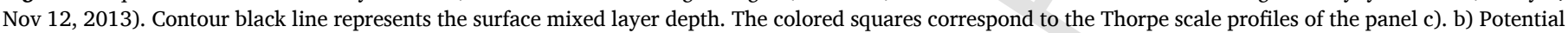

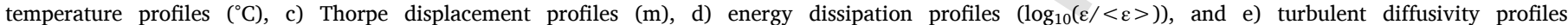
$\left(\log _{10}\left(\mathrm{~K}_{\mathrm{V} /}<\mathrm{K}_{\mathrm{V}}>\right)\right)$. The circles in each plot correspond to overturns in the profiles.

Echosounder). We observed that during sunrise/daytime conditions, the coefficients of determination were close to 0 , while for sunset/ nighttime conditions, the coefficients of determination were 0.66 and 0.81 for the entire dataset and the yoyo station, respectively.

The correlation between acoustic backscatter $(\mathrm{Sv})$ recorded by the echosounder at $200 \mathrm{kHz}$ and the Brunt-Väisälä frequency $\left(\mathrm{N}^{2}\right)$ was analyzed within the main zooplankton layer, which is characterized by strong acoustic reflectivity gradients (Figs. 5a and 6a). Considering the noise level of acoustic backscatter measurements, Sv were binned into classes of $5 \mathrm{~dB}$ before computing statistics of $\mathrm{N}^{2}$ and Sv over these bins. The outliers of each bin, above and below 1.5 times the upper and lower quartiles, were removed. A least squares regression method was then used to estimate the relationship between $\mathrm{Sv}\left(\mathrm{dB}\right.$ re $\left.\mathrm{m}^{-1}\right)$ and $\mathrm{N}^{2}\left(\mathrm{~s}^{-1}\right)$, from the bin-averaged values (Fig. 8a). A highly significant correlations (p-value $<0.01$ ) is found, between these two variables. Furthermore, the correlation is high, with a coefficient of determination $\left(\mathrm{r}^{2}\right)$ of 0.81 . The empirical linear equation derived from this correlation was used to derive $\mathrm{N}^{2}$ from acoustic data in the previously detected zooplankton layer. This allowed us to estimate the Richardson number, using the ADCP-derived vertical shear of velocity. Vertical sections of Richardson number are shown in Fig. 8b-c. For panel b, the Ri was estimated using the CTD-inferred Brunt-Väisälä frequency, while for panel c, we used a

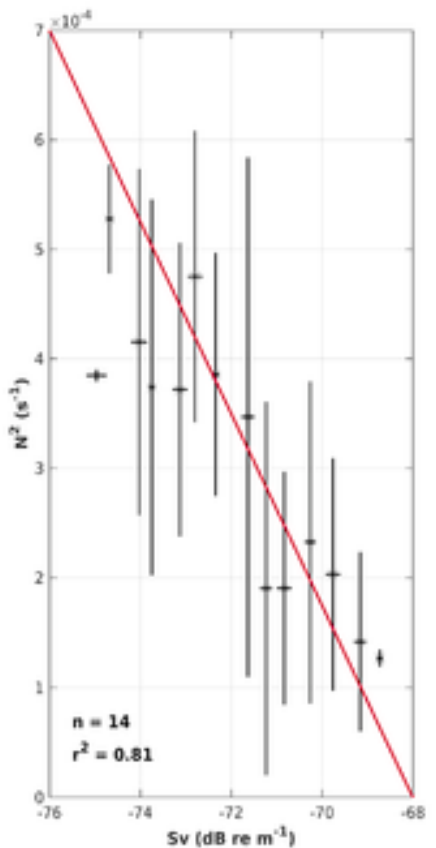

b

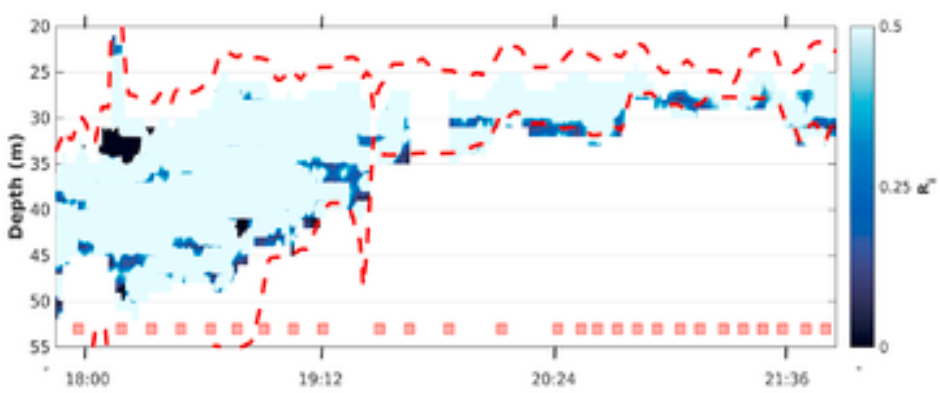

C

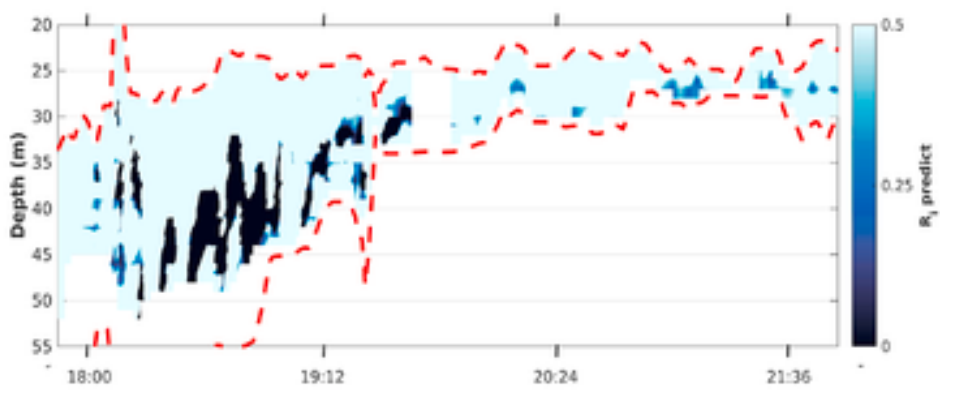

Fig. 8. a) Linear correlation between the acoustic signal from the echosounder (Sv) and the Brünt-Väisälä frequency ( $\left.\mathrm{N}^{2}\right)$ from CTD profiles. Black crosses correspond to the mean value of each bin, while horizontal and vertical black lines indicate the standard deviation for Sv and $\mathrm{N}^{2}$, respectively. The correlation was calculated within the layer of strong acoustic reflectivity gradients (Fig. 5a). b) Richardson number derived from the CTD and ADCP data. The red squares indicate the time of the CTD casts used for the computation. c) Richardson number derived from the echosounder and ADCP data. The red dashed lines correspond to the lower and upper limits of the strong acoustic reflectivity gradients. 
the echosounder-derived stratification. Low Richardson numbers (Fig. $8 c)$ coincide with the well-mixed patch $\left(R_{i}<0.25\right)$.

\section{Discussion}

4.1. The relevance of acoustics for detecting ISWs and quantifying induced mixing

The propagation of internal solitary waves on the continental shelf is difficult to observe due to their intermittence and because many processes may interact. Previous studies have shown the efficiency of the echosounder for internal wave tracking and description, including their size, wavelength and propagation speed (Apel, 2003; Bourgault et al., 2016; Li et al., 2018; Moum et al., 2003; Sandstrom et al., 1989; Serebryany, 2018). Here, the echosounder was also used to provide detailed location and timing data while measuring physical parameters of the water column. Echograms showed several nonlinear high-frequency oscillations (HFO) of the zooplankton layer, characterized by a period of about $15 \mathrm{~min}$ and an amplitude larger than $20 \mathrm{~m}$. The non-linearity of these oscillations, which occurred in phase with the tide, suggests that HFOs are signatures of ISWs propagation across the shelf, resulting from the disintegration of the internal tide caused by non-hydrostatic processes (Helfrich and Melville, 2006). These new observations in a poorly studied region suggest that ISWs might be ubiquitous across the shelf, with the recording of 12 HFOs in 18 campaign days. These observations are in agreement with the results of previous studies (Chang et al., 2021; Jackson et al., 2012). In this study, we demonstrated that the main layer of zooplankton is a proxy of the thermocline where these waves propagate. Sandstrom et al. (1989) showed that a significant increase in acoustic backscatter and temperature gradient variance are observed during the passage of ISWs over the continental shelf off Nova Scotia. Our results on the Moroccan continental shelf support their conclusions and extend them to a new geographical zone. We showed that the distribution of the main zooplankton layer in the water column, i.e., a layer marked by strong acoustic reflectivity gradients, was well correlated with the depth of the thermocline, with a coefficient of determination reaching 0.81 (Fig. 5). However, on the Moroccan shelf, the correlation between the thermocline and acoustic backscattering was only verified during sunset/nighttime conditions $\left(\mathrm{r}^{2}\right.$ between 0.66 and 0.81 ), while during the sunrise/daytime conditions, no correlation was found. However, solitons most commonly form from the decay of the internal tide and can therefore be generated at any time (day or night). We investigated possible explanations for the day-night difference in terms of the biological characteristics of zooplankton and our sampling parameters. During the day, zooplankton migrate deep into the ocean to escape from their predators. They are therefore spread over a greater depth, leading to a dilution in intensity of the acoustic signal received by the echosounder. The acoustic signal echo integration performed at $90 \mathrm{~dB}$, which facilitated the detection of strong acoustic reflectivity gradients in the zooplankton layer, was rather close to the noise level of the echosounder $(-100 \mathrm{~dB})$. Both the biological behavior of these organisms and the technical limitations of the acoustic instrument could contribute to the difficulty of detecting ISWs in daytime conditions. In addition, other geographically specific factors can hamper general parametrization for the detection of IWs, such as the intensity of upwelling or the type of zooplankton species concerned, which can have a strong seasonality (Romero et al., 2020; Romero and Fischer, 2017), and not react to the same acoustic frequency. Furthermore, the latter could explain the differences in acoustic backscatter response for the detection of the zooplankton layer, estimated at $-50 \mathrm{~dB}$ on the continental shelf off Nova Scotia (Sandstrom et al., 1989), but at around $-65 \mathrm{~dB}$ for the Moroccan shelf. The difficulty of detecting ISWs during daytime with acoustic instruments seems to be universal since most of the examples in the literature were obtained in nighttime conditions (Apel, 2003; Capet et al., 2017; Moum et al., 2003; Sandstrom et al., 1989).
The inability to determine a general parametrization of mixing in coastal zones (Schafstall et al., 2010) highlights the shortcomings of the quantification of these processes. In this study, we hypothesized that acoustic backscattering might be a proxy for density stratification. During nighttime conditions, the strong volume backscattering gradients (Sv) delineate the $\mathrm{N}^{2}$ maximum, as described by Sandstrom et al. (1989). For the first time, we showed the strong correlation between these two variables, with a high coefficient of determination $(0.81$; Fig. 8a). Associated with ADCP data, the volume acoustic backscatter allowed us to derive the Richardson number in the water column (Fig. $8 \mathrm{c}$ ), and this is in agreement with the Ri derived from the CTD data (Fig. 8b). This method provides greater spatial coverage and represents a significant saving of cost and time compared with CTD profile acquisition, which is necessary to derive $\mathrm{N}^{2}$. However, the correlation between these two variables was only verified in the area characterized by strong acoustic gradients (i.e., where the ISW train is observed), which represents the main layer of zooplankton in the water column (Fig. 5a). Among the three frequencies used for this work, it can be seen that the layers where the $200 \mathrm{kHz}$ showed the highest detection were the best correlated with ISWs. This frequency corresponds to species with an increasing frequency response (most likely crustaceans) (Lavery et al., 2007). This study shows that the acoustic backscatter levels provide a rapid and convenient tool to detect ISWs and to characterize Kelvin-Helmholtz instabilities, which can lead to mixing.

\subsection{Enhanced coastal mixing}

A recent study (Capet et al., 2017), suggests that ISWs over the shelf may affect the distribution of the southern Senegal upwelling center. The understanding and quantification of the processes induced by ISWs appears to be essential for the study of physical and biological interactions in complex environments such as the Moroccan upwelling. To improve our examination of the turbulence associated with ISW processes, we estimated the energy dissipation $(\varepsilon)$ and turbulent mixing rate $\left(\mathrm{K}_{\mathrm{v}}\right)$ using the method of Osborn (1980). Internal wave interactions with near-critical slopes, such as the one off the Moroccan shelf and the narrow steep channel, favor the onset of soliton generation. Here, the internal waves are prone to evolve into solitons of high frequency, which are clearly observed from the scatter signal by the echosounder (Fig. 3). These soliton observations suggest that M2 internal waves break into solitons due to the interaction with the slope break (14.2\% steepness), as shown in several studies (Da Silva and Magalhaes, 2016; Gerkema, 1996; Jones and Ivey, 2017). As the ISWs propagate into the shelf, some energy spreads into waves with shorter periods and generally smaller vertical scales, causing turbulence and mixing (Garrett, 2003). Our study shows that mixing is predominant in the surface layer due to the mechanical effects of wind and surface waves. However, secondary maxima of dissipation and diffusivity, associated with enhanced Thorpe displacements are observed near the thermocline, under the surface mixed layer, indicating an increase in diapycnal mixing. $\varepsilon$ values in the thermocline were reaching $\mathrm{O}\left(10^{-7} \mathrm{~W} \mathrm{~kg}^{-1}\right)$, where the amplitude of the ISWs trains were the highest (profiles from 17:50 to 18:18 UTC in Fig. 7a). Comparable values have been observed in other regions of the world such as the Senegal upwelling (Capet et al., 2017), continental shelf off Nova Scotia (Sandstrom et al., 1989), and Celtic Sea (Palmer et al., 2015). Combining observed velocity and stratification measurements shows turbulence $\left(R_{i}<0.25\right)$ in the water column under the surface mixed layer that favors the diapycnal mixing process. These observations suggest that on the Moroccan shelf, ubiquitous ISWs actively contribute to mixing of the water column and help to redistribute ocean properties. Even if the coupling of an Acoustic Doppler Current Profiler (ADCP) and a multifrequency echosounder makes it possible to efficiently assess the mixing process on large scales, more sophisticated methods would be needed to quantify precisely the intensity of local- 
ized mixing episodes induced by ISWs and their relationship with the shelf environment.

\section{Conclusion}

The observations of all available echograms indicate ubiquitous nonlinear internal wave activity over the Moroccan shelf, which is in agreement with observations carried out on the other parts of the NW African shelf (Senegal, Mauritania). We observed large-amplitude nonlinear ISWs of $40 \mathrm{~m}$ over a full water depth of $120 \mathrm{~m}$ on the Moroccan shelf. This study confirms that echosounders, mostly used for fishing activities and marine ecosystem studies, are convenient tools for detecting the activity and propagation of ISWs. The novelty of this work is the demonstration that, on the NW African shelf, the acoustic volume backscattering at $200 \mathrm{kHz}$ is a proxy of the density stratification during the night (with a coefficient of determination $\mathrm{r}^{2}=0.81$ ). Furthermore, our observations suggest that ISW dissipation over the shelf plays an important role in diapycnal mixing. Mixing due to internal wave soliton packets exhibits large spatial and temporal variability, but contributes to the overall mixing processes and is responsible for important intermittent variations in the thermocline position. Such variations are also associated with variations in the relocation of nutrients in the water column, which drives productivity. Finally, the use of an echosounder coupled to the ADCP in this study made estimates of the Richardson number - an indicator of mixing - possible on large spatial scales. Validation and application of this method in other coastal regions could be useful for refining and extending regional mixing parameterization in numerical models.

\section{Funding}

This work was financially supported by the French National Research Agency projects ANR-11-CEPL-0005 EPURE, ANR-17-EURE0015 ISblue and ANR-10-LABX-19 Labex-MER, by the interdisciplinary grant of IUEM and by the Laboratoire Géosciences Océan UMR6538.

\section{Declaration of competing interest}

The authors declare that they have no known competing financial interests or personal relationships that could have appeared to influence the work reported in this paper.

\section{Acknowledgements}

We thank the captain and crews of the R/V Antea for their help during the sampling. We thank Luis Tito de Morais, leader of ANR EPURE project and all the contributors. Thank you to reviewers, and the journal editor for their constructive and thoughtful comments and suggestions.

\section{References}

Alford, M.H., Peacock, T., MacKinnon, J.A., Nash, J.D., Buijsman, M.C., Centurioni, L.R., Chao, S.-Y., Chang, M.-H., Farmer, D.M., Fringer, O.B., 2015. The formation and fate of internal waves in the South China Sea. Nature 521, 65-69.

Alford, M.H., Pinkel, R., 2000. Observations of overturning in the thermocline: the context of ocean mixing. J. Phys. Oceanogr. 30, 805-832.

Apel, J.R., 2003. A new analytical model for internal solitons in the ocean. J. Phys. Oceanogr. 33, 2247-2269.

Arístegui, J., Barton, E.D., Álvarez-Salgado, X.A., Santos, A.M.P., Figueiras, F.G., Kifani, S., Hernández-León, S., Mason, E., Machú, E., Demarcq, H., 2009. Sub-regional ecosystem variability in the Canary Current upwelling. Prog. Oceanogr. 83, 33-48. https://doi.org/10.1016/j.pocean.2009.07.031.

Baines, P., 1973. The generation of internal tides by flat-bump topography. In: Presented at the Deep Sea Research and Oceanographic Abstracts. Elsevier, pp. 179-205. Bertrand, A., Ballon, M., Chaigneau, A., 2010. Acoustic observation of living organisms reveals the upper limit of the oxygen minimum zone. PloS One 5, e10330.

Bourgault, D., Galbraith, P.S., Chavanne, C., 2016. Generation of internal solitary waves by frontally forced intrusions in geophysical flows. Nat. Commun. 7, 1-9.

Capet, X., Estrade, P., Machu, É., Ndoye, S., Grelet, J., Lazar, A., Marié, L., Dausse, D.,
Brehmer, P., 2017. On the dynamics of the southern Senegal upwelling center: observed variability from synoptic to superinertial scales. J. Phys. Oceanogr. 47, 155-180.

Chang, M.-H., Cheng, Y.-H., Yang, Y.J., Jan, S., Ramp, S.R., Reeder, D.B., Hsieh, W.-T., Ko, D.S., Davis, K.A., Shao, H.-J., 2021. Direct measurements reveal instabilities and turbulence within large amplitude internal solitary waves beneath the ocean. Commun. Earth Environ. 2, 1-10.

Cropper, T.E., Hanna, E., Bigg, G.R., 2014. Spatial and temporal seasonal trends in coastal upwelling off Northwest Africa, 1981-2012. Deep Sea Res. Oceanogr. Res. Pap. 86, 94-111. https://doi.org/10.1016/j.dsr.2014.01.007.

Da Silva, J., Magalhaes, J., 2016. Internal solitons in the Andaman Sea: a new look at an old problem. In: Presented at the Remote Sensing of the Ocean, Sea Ice, Coastal Waters, and Large Water Regions 2016. International Society for Optics and Photonics, p. 999907.

de Boyer Montégut, C., Madec, G., Fischer, A.S., Lazar, A., Iudicone, D., 2004. Mixed layer depth over the global ocean: an examination of profile data and a profile-based climatology. J. Geophys. Res.: Oceans 109.

de Lavergne, C., Falahat, S., Madec, G., Roquet, F., Nycander, J., Vic, C., 2019. Toward global maps of internal tide energy sinks. Ocean Model. 137, 52-75.

Dillon, T.M., 1982. Vertical overturns: a comparison of Thorpe and Ozmidov length scales. J. Geophys. Res.: Oceans 87, 9601-9613.

Foote, K.G., 1987. Fish target strengths for use in echo integrator surveys. J. Acoust. Soc. Am. 82, 981-987.

Garrett, C., 2003. Internal tides and ocean mixing. Science 301, 1858-1859.

Garrett, C., Kunze, E., 2007. Internal tide generation in the deep ocean. Annu. Rev. Fluid Mech. 39, 57-87.

Garrett, C., Munk, W., 1979. Internal waves in the ocean. Annu. Rev. Fluid Mech. 11, 339-369.

Garrett, C., Munk, W., 1975. Space-time scales of internal waves: a progress report. J. Geophys. Res. 80, 291-297.

Gerkema, T., 1996. A unified model for the generation and fission of internal tides in a rotating ocean. J. Mar. Res. 54, 421-450.

Grados, D., Bertrand, A., Colas, F., Echevin, V., Chaigneau, A., Gutiérrez, D., Vargas, G., Fablet, R., 2016. Spatial and seasonal patterns of fine-scale to mesoscale upper ocean dynamics in an Eastern Boundary Current System. Prog. Oceanogr. 142, 105-116. Hamann, M.M., Alford, M.H., Mickett, J.B., 2018. Generation and propagation of nonlinear internal waves in sheared currents over the Washington continental shelf. J. Geophys. Res.: Oceans 123, 2381-2400.

Held, P., Bartholomä-Schrottke, K., Bartholomä, A., 2019. Indications for the transition of Kelvin-Helmholtz instabilities into propagating internal waves in a high turbid estuary and their effect on the stratification stability. Geo Mar. Lett. 39, 149-159.

Helfrich, K.R., Melville, W.K., 2006. Long nonlinear internal waves. Annu. Rev. Fluid Mech. 38, 395-425.

Holloway, P.E., 1987. Internal hydraulic jumps and solitons at a shelf break region on the Australian North West Shelf. J. Geophys. Res.: Oceans 92, 5405-5416.

Howard, L.N., 1961. Note on a paper of John W. Miles. J. Fluid Mech. 10, 509-512.

Jackson, C.R., Da Silva, J.C., Jeans, G., 2012. The generation of nonlinear internal waves. Oceanography 25, 108-123.

Jones, N., Ivey, G., Rayson, M., Kelly, S., 2020. Mixing driven by breaking nonlinear internal waves. Geophys. Res. Lett. 47, e2020GL089591.

Jones, N.L., Ivey, G.N., 2017. Internal waves. Encycl. Maritime Offshore Eng. 1-12.

Lamb, K.G., 2014. Internal wave breaking and dissipation mechanisms on the continental slope/shelf. Annu. Rev. Fluid Mech. 46, 231-254.

Lavery, A.C., Wiebe, P.H., Stanton, T.K., Lawson, G.L., Benfield, M.C., Copley, N., 2007.

Determining dominant scatterers of sound in mixed zooplankton populations. J. Acoust. Soc. Am. 122, 3304-3326.

Lennert-Cody, C.E., Franks, P.J., 1999. Plankton patchiness in high-frequency internal waves. Mar. Ecol. Prog. Ser. 186, 59-66.

Li, L., Pawlowicz, R., Wang, C., 2018. Seasonal variability and generation mechanisms of nonlinear internal waves in the strait of Georgia. J. Geophys. Res.: Oceans 123, 5706-5726.

Llewellyn Smith, S.G., Young, W., 2002. Conversion of the barotropic tide. J. Phys. Oceanogr. 32, 1554-1566.

MacKinnon, J.A., Zhao, Z., Whalen, C.B., Waterhouse, A.F., Trossman, D.S., Sun, O.M., St Laurent, L.C., Simmons, H.L., Polzin, K., Pinkel, R., 2017. Climate process team on internal wave-driven ocean mixing. Bull. Am. Meteorol. Soc. 98, 2429-2454. MacLennan, D.N., Fernandes, P.G., Dalen, J., 2002. A consistent approach to definitions and symbols in fisheries acoustics. ICES (Int. Counc. Explor. Sea) J. Mar. Sci. 59, 365-369.

McDougall, T.J., Barker, P.M., 2011. Getting started with TEOS-10 and the Gibbs Seawater (GSW) oceanographic toolbox. SCOR/IAPSO WG 127, 1-28.

Miles, J.W., 1961. On the stability of heterogeneous shear flows. J. Fluid Mech. 10, 496-508.

Moum, J.N., 1996. Efficiency of mixing in the main thermocline. J. Geophys. Res.: Oceans 101, 12057-12069.

Moum, J.N., Farmer, D.M., Smyth, W.D., Armi, L., Vagle, S., 2003. Structure and generation of turbulence at interfaces strained by internal solitary waves propagating shoreward over the continental shelf. J. Phys. Oceanogr. 33, 2093-2112.

Müller, P., Briscoe, M., 2000. Diapycnal mixing and internal waves. Oceanography 13, 98-103.

Nash, J.D., Kunze, E., Toole, J.M., Schmitt, R.W., 2004. Internal tide reflection and turbulent mixing on the continental slope. J. Phys. Oceanogr. 34, 1117-1134. Nash, J.D., Shroyer, E.L., Kelly, S.M., Inall, M.E., Duda, T.F., Levine, M.D., Jones, N.L., Musgrave, R.C., 2012. Are any coastal internal tides predictable?. Oceanography 25, 80-95.

Ozmidov, R.V., 1965. On the turbulent exchange in a stably stratified ocean. Izvestiya Acad. Sci. USSR, Atmos. Ocean. Phys. 1, 861-871. 
Palmer, M.R., Stephenson, G.R., Inall, M.E., Balfour, C., Düsterhus, A., Green, J.A.M., 2015. Turbulence and mixing by internal waves in the Celtic Sea determined from ocean glider microstructure measurements. J. Mar. Syst. 144, 57-69.

Perrot, Y., Brehmer, P., Habasque, J., Roudaut, G., Behagle, N., Sarré, A., LebourgesDhaussy, A., 2018. Matecho: an open-source tool for processing fisheries acoustics data. Acoust Aust. 46, 241-248.

Pineda, J., Rouse, S., Starczak, V., Helfrich, K., Wiley, D., 2020. Response of small sharks to nonlinear internal waves. Limnol. Oceanogr. 65, 707-716.

Rippeth, T.P., Palmer, M.R., Simpson, J.H., Fisher, N.R., Sharples, J., 2005. Thermocline mixing in summer stratified continental shelf seas. Geophys. Res. Lett. 32.

Romero, O.E., Baumann, K.-H., Zonneveld, K.A., Donner, B., Hefter, J., Hamady, B.

Pospelova, V., Fischer, G., 2020. Flux variability of phyto-and zooplankton communities in the Mauritanian coastal upwelling between 2003 and 2008. Biogeosciences 17, $187-214$.

Romero, O.E., Fischer, G., 2017. Shift in the species composition of the diatom community in the eutrophic Mauritanian coastal upwelling: results from a multi-year sediment trap experiment (2003-2010). Prog. Oceanogr. 159, 31-44.

Sandstrom, H., Elliot, J.A., Cchrane, N.A., 1989. Observing groups of solitary internal waves and turbulence with BATFISH and echo-sounder. J. Phys. Oceanogr. 19, 987-997. Sandstrom, H., Oakey, N.S., 1995. Dissipation in internal tides and solitary waves. J. Phys. Oceanogr. 25, 604-614.

Schafstall, J., Dengler, M., Brandt, P., Bange, H., 2010. Tidal-induced mixing and diapycnal nutrient fluxes in the Mauritanian upwelling region. J. Geophys. Res.: Oceans 115.

Serebryany, A.N., 2018. Mode 2 internal waves in the ocean: Evidences from observations. In: The Ocean in Motion. Springer, pp. 211-219.
Smyth, W.D., Moum, J.N., 2012. Ocean mixing by Kelvin-Helmholtz instability. Oceanography 25, 140-149.

St Laurent, L., Garrett, C., 2002. The role of internal tides in mixing the deep ocean. J. Phys. Oceanogr. 32, 2882-2899.

Thorpe, S.A., 1977. Turbulence and mixing in a Scottish loch. Phil. Trans. Roy. Soc. Lond. Math. Phys. Sci. 286, 125-181.

van Haren, H., 2020. Challenger Deep internal wave turbulence events. Deep Sea Res. Oceanogr. Res. Pap. 165, 103400.

Vic, C., Garabato, A.C.N., Green, J.M., Waterhouse, A.F., Zhao, Z., Melet, A., De Lavergne, C., Buijsman, M.C., Stephenson, G.R., 2019. Deep-ocean mixing driven by small-scale internal tides. Nat. Commun. 10, 1-9.

Vlasenko, V.I., Ivanov, V.A., Krasin, I.G., Lisichenok, A.D., 1996. Study of intensive internal waves in the shelf zone of Morocco. Phys. Oceanogr. 7, 281-298.

Warren, J.D., Stanton, T.K., Wiebe, P.H., Seim, H.E., 2003. Inference of biological and physical parameters in an internal wave using multiple-frequency, acoustic-scattering data. ICES (Int. Counc. Explor. Sea) J. Mar. Sci. 60, 1033-1046.

Wesson, J., Gregg, M., 1994. Mixing at Camarinal sill in the strait of Gibraltar. J. Geophys. Res.: Oceans 99, 9847-9878.

Wunsch, C., 1975. Internal tides in the ocean. Rev. Geophys. 13, 167-182.

Yuan, C., Grimshaw, R., Johnson, E., Whitfield, A., 2020. Generation of nonlinear internal waves by flow over topography: Rotational effects. Phys. Rev. 101, 033104.

Zulberti, A., Jones, N., Ivey, G., 2020. Observations of enhanced sediment Transport by nonlinear internal waves. Geophys. Res. Lett. 47, e2020GL088499. 